\title{
Incidence of early pregnancy complications, management protocols and its outcome in patients at Gujarat Adani Institute of Medical Science, Bhuj, Kutch, Gujarat, India
}

\author{
Akansha, Nagajan Bhadarka* \\ Department of Obstetrics and Gynecology, Gujarat Adani Institute of Medical Science, Bhuj, Kutch, Gujarat, India
}

Received: 27 July 2017

Accepted: 29 July 2017

*Correspondence:

Dr. Nagajan Bhadarka,

E-mail: researchguide86@gmail.com

Copyright: $\odot$ the author(s), publisher and licensee Medip Academy. This is an open-access article distributed under the terms of the Creative Commons Attribution Non-Commercial License, which permits unrestricted non-commercial use, distribution, and reproduction in any medium, provided the original work is properly cited.

\begin{abstract}
Background: Early Pregnancy Complications can cause significant morbidity and mortality. Pregnant women an present with $\mathrm{h} / \mathrm{o}$ amenorrhea, abdominal pain, vaginal bleeding or incidental scan finding of missed abortion, ectopic pregnancy and vesicular mole, features of hypermesis gravidorum like fatigue, nausea, vomiting, dryness and diminished urine output. The objective of present study was to analyze the incidence of various early pregnancy complications, assess the protocols for diagnosing these complications and their management.

Methods: Present study was conducted at the Department of Obstetrics and Gynecology, Gujarat Adani Institute of Medical Science, Bhuj, Kutch, Gujarat. All the women with first trimester pregnancy with different complications were included in this study while those women with uneventful first trimester were excluded. The inducted women were registered on pre-designed proforma. Studied variables including demographic details, gestational period, type of complications, risk factors, treatment and outcome.

Results: Out of 740 total admissions 439 abortions of which incomplete abortion was 262, missed abortions were 132, threatened abortion 42 and 3 cases of septic abortion, ectopic pregnancy 154, molar pregnancy33, hyperemesis 31 . There were about 63 cases of non-pregnancy related complication reported during early pregnancy like 31 with UTI, 9 with renal colic, 2 cases of appendicitis, four cases of asymptomatic cholelithiasis, 2 cases of hepatitis, 5 cases of ovarian cyst complicating pregnancy, 2 cases of ovarian torsion. Their mean age was $30.8+6.8$ years.

Conclusions: Study was successful in creating a confidence among trainees when following the recommended protocols as well as delivering clinical benefits to the hospital, patients and staff. Early gynecological consultation and bedside ultrasound scanning within the emergency department were key requirements for any emergency concerns.
\end{abstract}

Keywords: Abortions, Gynecology, Pregnancy, Ultrasound

\section{INTRODUCTION}

Early Pregnancy Complications can cause significant morbidity and mortality. Pregnant women present with $\mathrm{h} / \mathrm{o}$ amenorrhea, abdominal pain, vaginal bleeding or incidental scan finding of missed abortion, ectopic pregnancy and vesicular mole, features of hypermesis gravidorum like fatigue, nausea, vomiting, dryness and diminished urine output. Early pregnancy period is usually having some physiological symptoms some of the women may show an exaggeration of nausea and vomiting starts by $6^{\text {th }}$ to $8^{\text {th }}$ week subsides by $12^{\text {th }}$ week for most. ${ }^{1,2}$

Few patients might have protracted vomiting incapacitating normalcy causing dehydration, acidosis and electrolyte imbalance, there is loss of weight, emaciation, azotemia and wernickes encephalopathy, 
treatment for mild forms include reassurance, dietic regulations and anti-emetics. For hyper emesis patient hospitalized. Depleted carbohydrate stores are replaced by glucose fluids, NPO for 24 to 48 hrs, IV fluid with adequate sodium, potassium, chloride, lactate, bicarbonate glucose and water, parenterally along with antiemetic.

Oral feed is started after clinical improvement. if hyper emesis persists suspect and investigate other causes cholecystitis and pyelonephritis. Anti-emetics of choice are anti - histamines promethacine, cyclizin, cinnarizin, doxylamine. Metaclopramide is a first line drug except for its extra pyramidal symptoms. Ondensetron is a second line choice but safety and efficacy are good. ${ }^{3,4}$

Abortions less than 10 weeks are due to chromosomal factors, maternal diseases or infections. Different type of abortion needs appropriate management. In threatened abortion, there is mild vaginal bleeding, crampy abdominal pain, Ultrasound study reveals viable pregnancy cardiac activity is seen. Threatened abortion needs rest and about $75 \%$ of cases will continue normally there is slightly higher risk of premature labour, IUGR and APH. In a viable pregnancy if the cervical os is open, production of conception is bound to expel. Here surgical evacuation is opted, if bleeding is severe. Cervix is open even after product of conception expulsion. Usually suction evacuation is preferred over instrumental evacuation., ${ }^{5,6}$ Occasionally blood transfusions are needed.

In contrast missed abortions are non - viable pregnancy where cervical os is closed with only mild spotting and mild abdominal pain. For GA, less than 10 Weeks evacuation is done after priming the cervix with Prostaglandins, for GA more than 12 Wks. Medical modality with post expulsion gentle checks curette is followed and surgical evacuation is done as and when needed.

Another life-threatening complication is ectopic pregnancy $95 \%$ occur in fallopian tube. Most of the cases present to emergency department in a state of shock. Ectopic pregnancy is obvious if there is a massive free fluid by screening ultrasound. Usually needling is done to confirm hemoperitoneum and patient shifted for emergent laparotomy and proceed. Some cases may report by outside referral with USS clearly mentioning about ectopic pregnancy, invariably all cases need blood transfusion. If patient is stable and un-ruptured ectopic of size less than $3 \mathrm{~cm}$ medical management is done. Drug used is methotrexate either single dose or multi dose therapy is choose.

With widespread usage of ultrasound study nowadays vesicular mole is diagnosed early and being referred before they produce alarming signs and symptoms. Therapeutic option for vesicular mole is suction evacuation with concurrent oxytocin. Important aspect of treatment is follow up and meticulous search for features of metastasis for 6 months by clinical, radiological examination and advice contraception for $1 \mathrm{yr}$.

Aim of the present study is to analyse the incidence of various early pregnancy complications, assess the protocols for diagnosing these complications and their management.

\section{METHODS}

Present study is an observational study conducted at Department of Obstetrics and Gynecology, Gujarat Adani Institute of Medical Science Bhuj, Kutch over a period of one year. All patients admitted with complaints in early pregnancy like bleeding per vaginum, hyper emesis, pain abdomen, vaginal discharge, medical complications like severe anemia, cardiac disorders, breathlessness, diabetes were included in the study. Patients with spotting following delayed cycles, and GA more than 12 Weeks were excluded from this study. Ethical clearance was taken from the institutional ethics board and informed consent was obtained from all the participants in the study.

All patient details like age, parity, gestational age, complaints, history of drug intake, associated risk factors, previous treatment details; previous ultrasound reports were collected using a detailed questionnaire. Vital parameters like pulse rate, blood pressure, temperature was recorded. The patients were then subjected to blood investigations to find out their hemoglobin, blood sugar, serum electrolyte levels. An ultrasound was done to find out ectopic gestation, missed abortion, incomplete abortion and free fluid. Per abdominal examination to elicit tenderness in RIF to identify appendicitis examination to fnd out uterine size, cervical dilation, forniceal tenderness, bleeding was done. The results of examination recorded. Patients with ectopic gestation, appendicitis were managed surgically if symptomatic or medically when asymptomatic. Patients with septic abortion, missed abortion, incomplete abortion were managed with evacuation of products of conception. Patients with medical disorders were evaluated and treated for the underlying condition. Patients admitted with threatened abortion were managed with micronized progesterone supplementation, hyper emesis with antiemetics and fluid replacement, abdominal pain with analgesics, antibiotics, antispasmodics depending on underlying etiology.

\section{RESULTS}

A total of 740 patients were admitted with various complaints and less than 12 wks GA during the study period. Of these patients, 94 did not require any intervention. 10 patients with acute abdomen had findings suggestive of appendicitis and referred to surgical department. The incidence of various early pregnancy complications was shown in Table 1. 
Table 1: Incidence of various early pregnancy complications.

\begin{tabular}{|l|l|}
\hline Complaints & No. of patients \\
\hline Vaginal bleeding & 421 \\
\hline Lower abdominal pain & 145 \\
\hline Hyperemasis & 77 \\
\hline Pregnancy with medical complications & 41 \\
\hline Incidental USG findings & 27 \\
\hline Pregnancy with surgical complications & 19 \\
\hline
\end{tabular}

Most common one is vaginal bleeding. Diagnosis among patients with vaginal bleeding: as in Table 2, most common presentation is the incomplete abortion which need post expulsion curettage Patients with the diagnosis of miscarriage were the commonly presented with the acute abdomen.

Table 2: incidence of presentation of the cases.

\begin{tabular}{|ll|}
\hline Diagnosis & No. of patients \\
\hline Missed abortion & 131 \\
\hline Inevitable abortion & 63 \\
\hline Incomplete abortion & 260 \\
\hline Complete abortion & 51 \\
\hline Threatened abortion & 41 \\
\hline Ectopic gestation & 152 \\
\hline GTD & 3 \\
\hline
\end{tabular}

\section{DISCUSSION}

There appear to be various risk factors for early pregnancy complications. Analyzing the data of 730 women, it is found that these complaints are more common among primi gravida than multigravida, likewise adolescent pregnancy also has increased number of complaints. ${ }^{7-9}$ This could be attributed to the fact of early marriage, uncorrected anemia, and inadequate physical and mental development of the mother. The most common complication in first trimester in this study is abortion that follows history of vaginal bleeding. 57\% patients were admitted in their first trimester for complaints of vaginal bleeding.

Among patients with vaginal bleeding, $25 \%$ had incomplete abortion, $17 \%$ had missed abortion, $15 \%$ had inevitable abortion, $16 \%$ had threatened abortion, and $12 \%$ had ectopic pregnancy. This is comparable to study by Khaskheli et al where the most common complication was abortion in $76.52 \%$ cases. $^{10,11}$

The rate of spontaneous abortion in 50\% during the first 20 weeks of gestation. In present study, the incidence of abortion was $40 \%$. The management for patients presenting with vaginal bleeding involves a transvaginal ultrasound study to ensure fetal viability. In cases of threatened abortion, patients were managed with bed rest, folic acid supplementation, micronized progesterone supple mentation and allowed to continue pregnancy. The incidence of threatened abortion was 30\%. This is similar to study done by Choi et al where the incidence of threatened abortion was 33\%, and these were managed with progesterone supplementation and $77 \%$ of these carried to term. ${ }^{12,13}$ In present study, $12 \%$ of these patients suffered incomplete abortion despite progesterone supplementation.

For patients without fetal viability, the management was termination of pregnancy. When there was a missed abortion or incomplete abortion, they were given medical termination with mifepristone and misoprostol regimen. Patients not expelled with medical termination, were preceded to manual vacuum aspiration with check curettage. Those with complete abortion were reviewed with ultrasound and given antibiotic coverage.

The incidence of ectopic pregnancy has risen from 4.5 per 1000 to 19.7 per 1000 over the past decade. In this study, the incidence of ectopic pregnancy was $11 \%$. Ectopic pregnancies presented with vaginal bleeding in $60 \%$ and abdominal pain in $40 \%$. State and site of ectopic confirmed by ultrasound and culdocentesis. When the ectopic was unruptured as in $2 \%$ of cases, they were given methotrexate. When ruptured, to maintain hemodynamic stability of the mother, they were managed with emergency laparatomy, resection of site of ectopic and blood products.

All ectopic pregnancies were discharged in good condition on day 7. There was a total of 33 molar pregnancies in our study period. No incidence of gestational trophoblastic neoplasia. All molar pregnancies after evaluation with thyroid profile to rule out thyrotoxicosis, chest x-ray, were managed with suction evacuation of products of conception. Products sent to HPE to confirm hydatidiform mole and rule out malignancy. ${ }^{14-16} 10 \%$ cases were admitted for hyper emesis. They were managed with blood electrolyte monitoring, adequate hydration, antiemetics and antacids. The patients responded to this line of therapy and symptoms subsided by 2 to 5 days. Khaskheli et al study had incidence of diabetes in $9.09 \%$ and hypertension in $18.18 \%$ among the patients. ${ }^{17-19}$ Ganchimeg et al study had $1.9 \%$ preeclampsia, $14.3 \%$ severe anemia among early pregnant mother. ${ }^{15}$ In current study incidence of anemia was $42 \%$, preeclampsia was $1 \%$ and diabetes was $1 \%$. When presented in early gestation with uncontrolled blood sugar values or uncontrolled BP, they were advised termination. Other patients were managed with antihypertensive and low dose aspirin for hypertension, switch over to Inj. Insulin for diabetes and blood transfusion, cardiac status monitoring for severe anemia. $3 \%$ patients presented with surgical complications. Of these 2 patients with acute abdominal pain had appendicitis and were managed surgically by appendicectomy. The remaining patients had findings suggestive of renal colic which was managed with antispasmodics, plenty of fluids, analgesics and discharged. $4 \%$ patients presented with varied incidental 
ultrasound fndings ranging from missed abortion, ectopic gestation to ovarian cyst.

None of the patients had severe morbidity or mortality in the early pregnancy period during the study. This proves that monitoring of early pregnancy complications with adequate investigations and examinations and intervening medically or surgically as required, can improve the general outcome for the mother. The most significant co morbidity was anemia of varying severity. On long term follow up, it showed that early correction of anemia improves the outcome of pregnancy and prevents the occurrence of refractory anemia at a later gestational age. ${ }^{20}$

\section{CONCLUSION}

The complications of early pregnancy may vary in presentation. Ectopic pregnancies and miscarriage may be very difficult to differentiate from one another. The primary objective of the emergency physician should be to rule out an ectopic pregnancy since it is a major cause of maternal morbidity and mortality. Often, the diagnosis is left in question even with appropriate lab testing and ultrasound results. Patients may require serial evaluations and specialty consultation. Any patient at risk for fetomaternal transfusion should receive anti-D immune globulin for prophylaxis. If an ectopic pregnancy is diagnosed, methotrexate should be reserved for those patients who qualify, and their ability to follow-up should be considered.

\section{Funding: No funding sources}

Conflict of interest: None declared

Ethical approval: The study was approved by the Institutional Ethics Committee

\section{REFERENCES}

1. Khaskheli M, Baloch S, baloch AS. Risk factors in early pregnancy complications. J Coll Physicians Surg Pak. 2010;20(11):744-7.

2. Dart R. Role of pelvic ultrasonography in evaluation of first trimester pregnancy. Ann Emerg Med. 1999;33:310-20.

3. Choi H, Blaivas M, Lambert MJ. Gestational outcome in patients with first- trimester pregnancy complications and ultrasound- confirmed live intrauterine pregnancy. Acad Emer Med. 2000;7(2):200-3.

4. Morin L, Cargill YM, Glanc P. Ultrasound evaluation of first trimester complications of pregnancy. J Obstet Gynaecol Canada. 2016;38(10):982-8.

5. Ganchimeg, Morisakhi, Laopaiboon. Pregnancy and childbirth outcome: A world health organization multicountry study. BJOG. 2014;121(Suppl. 1):40-8.
6. Why Mothers Die 1997-99. The fifth report of confldential enquiries into maternal deaths in the United Kingdom 1997-99. London: RCOG Press; 2001.

7. Sowter MC, Farquhar CM. Ectopic Pregnancy: An Updat.e Current Opin Obstet Gynecol. 2004;16:289-93.

8. Van Den Eeden SK, Shan J, Bruce C, Glasser M. Ectopic pregnancy rate and treatment utilization in a large managed care organization. Obstet Gynecol. 2005;105(5, Part 1):1052-7.

9. WHO/UNFPA/UNICEF/World Bank. Maternal mortality 2005. Estimates developed by WHO, UNICEF, UNFPA, and the World Bank. Geneva: The World Health Organization; 2007.

10. Abou Zahr C, Wardlaw T. Maternal mortality at the End of a decade: signs of progress? Bull World Health Organ. 2001;79(6):561-8.

11. WHO/UNFPA/UNICEF/World Bank. Reduction of maternal mortality: A joint WHO/UNFPA/UNICEF/World Bank statement. Geneva: The World Health Organization; 1999.

12. Ronsmans C, Filippi V. Beyond the Numbers: Reviewing Maternal Deaths and Complication to Make Pregnancy Safer. Reviewing severe maternal morbidity: learning from survivors from life-threatening complications. (Chapter 7) Geneva: World Health Organization. 2004:103-124.

13. Mantel GD, Buchmann E, Rees H, Pattinson RC. Severe acute maternal morbidity: a pilot study of a deflnition for a near miss. Br J Obstet Gynecol. 1998;105:985-990.

14. Tunçalp O, Hindin MJ, Souza JP, Chou D, Say L. The prevalence of maternal near miss: a systematic review. Br J Obstet Gynaecol. 2012;119:653-61.

15. Say L, Souza JP, Pattinson RC. WHO working group on Maternal Mortality and Morbidity classifications. Maternal near miss-towards a standard tool for monitoring quality of maternal health care. Best Pract Res Clin Obstet Gynecol. 2009;23:287-96.

16. Pattison RC, Buchmann E, Mantel G, Schoon M, Rees H. Can enquires into severe acute maternal morbidity act as surrogate for maternal death enquires? BJOG. 2003;110:889-93.

17. Souza J, Cecatti JG, Hardy EF, Serruya SJ, Amaral E. Appropriate criteria for identification of near miss maternal morbidity in tertiary care facilities: a cross sectional study. BMC Pregnancy Childbirth. 2007;7:20.

18. Waterstone M, Bewley S, Wolfe C. Incidence and predictors of severe obstetric morbidity: case control study. Br Med J. 2001;322:1084-94.

19. Paruk F, Moodley J. Severe obstetric morbidity. Curr Opin Obstet Gynecol. 2001;13:563-8.

20. Goffman D, Madden RC, Harrison EA, Merkatz IR, Chazotte C. Predictors of maternal mortality and nearmiss maternal morbidity. J Perinatol. 2007;27:597-601.

Cite this article as: Akansha, Bhadarka N. Incidence of early pregnancy complications, management protocols and its outcome in patients at Gujarat Adani Institute of Medical Science, Bhuj, Kutch, Gujarat, India. Int J Reprod Contracept Obstet Gynecol 2017;6:3837-40. 